\title{
A Fiber Optic Wind Vane (U)
}

by

M. J. Parker

Westinghouse Savannah River Company

Savannah River Site

Aiken, South Carolina 29808

M. Hevertv

Met One Instruments

OR USA

DOE Contract No. DE-AC09-89SR18035

This paper was prepared in connection with work done under the above contract number with the U.S. Department of Energy. By acceptance of this paper, the publisher and/or recipient acknowledges the U.S. Government's right to retain a nonexclusive; royalty-free license in and to any copyright covering this paper, along with the right to reproduce and to authorize others to reproduce all or part of the copyrighted paper. 


\section{DISCLAIMER}

This report was prepared as an account of work sponsored by an agency of the United States Govermment. Neither the United States Government nor any agency thereof, nor any of their employees, makes any warranty, express or implied, or assumes any legal liability or responsibility for the accuracy, completeness, or usefulness of any information, apparatus, product, or process disclosed, or represents that its use would not infringe privately owned rights. Reference herein to any specific commercial product, process, or service by trade name, trademark, manufacturer, or otherwise does not necessarily constitute or imply its endorsement, recommendation, or favoring by the United States Government or any agency thereof. The views and opinions of authors expressed herein do not necessarily state or reflect those of the United States Government or any agency thereof.

This report has been reproduced directly from the best available copy.

Available to DOE and DOE contractors from the Office of Scientific and Technical Information, P.O. Box 62, Oak Ridge, TN 37831; prices available from (615) 57.6-8401.

Available to the public from the National Technical-Information Service, U.S. Department of Commerce, 5285 Port Royal Road, Springfield, VA 22161. 


\section{DISCLAMIER}

Portions of this document may be illegible in electronic image produets. Images are produced from the best available original docoment. 
Distribution list for:

\section{A Fiber Optic Wind Vane (U) WSRC-TR-97-0010}

Dr. Susan Wood, 773-A

T. G. Wright, 773-A

J. G. Irwin, SRFS 760-G

P. T. Deason, 773-A

J. D. Heffner, 735-16A

R. E. DeBusk, 706-8C

D. B. Moore-Shedrow, 773-A

C. D. Strain, 773-A

A. L. Boni, 773-A

A. J. Garrett, 773-A

R. P. Addis, 773-A

E. C. Goodson, DOE 703-46A

J. E. Halverson, 735-A D-Wing

W. A. Emel, 735-A D-Wing

C. H. Hunter, 773-A

R. J. Kurzeja, 773-A

M. J. Parker, 735-7A

J. Stewart, 773-A

A. H. Weber, 773-A

R. Buckley, 773-A

J. T. Hamilton, 735-7A

R. F. Holland, 735-7A

F. A. Cheek, 773-A

A. G. Phillips, 703-43A

W. C. Carlton, 773-A

A. A. Simpkins, 773-A

G. T. Jannik, 773-A

C. E. Murphy, Jr., 773-42A

Ken O'Dell, 773-A

Karen Azzaro, 773-41A

Jean Campbell, 999-W

Brenda Young, 730-B

Bob Lusky, 730-B

Frank Utsch, 773-41A

Jean Mobley (Librarian), SREL 737-A

Jamie Scott, USFS 760-5G

Larry Bryan, SREL 737-A

ATG files, 773-A (4)

Tom Pottberg, Met One Instruments

Matthew Heverly, Met One Instruments

50 extra copies to be delivered to M. J. Parker, 735-7A 


\section{Westinghouse Savannah River Company}

1993 S. Centennial Avenue

Aiken, SC 29803

April 3, 1997

Matlew Parker

Building 735-7A

Westinghouse Savanmah River Company (US DepL of Energy):

Met One Instruments has revicwed Matuliew J. Parker's A Fiber Optic Wind Vane (U) for the completion of CRADA CR-94-015 and found that it meets the rcquirements agreed upon. Met One Instruments Inc. gives its approval for the disclosure of CRADA CR-94-015 information in the above incntioned publication in accordance with Article XII of Cooperative Research and Development Agreement CR-94. 015.

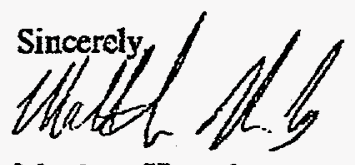

Matthew Hevcrly Mechanical Engineer Met One Instruments Inc. $1600 \mathrm{NW}$ Washington BLVD

Grants Pass, OR 97526 
WSRC-TR-97-0010

February 1997

\section{A Fiber Optic Wind Vane (U)}

M. J. Parker

Westinghouse Savannah River Company

M. Heverly

Met One Instrument, Incorporated

Prepared for the U.S. Department of Energy under contract no. DE-AC09-89SR18035 


\section{Contents}

\section{Executive Summary 1}

Introduction 1

Sensor Design 1

Wincl Tunnel Tests 4

Dynamic Vane Bias 6

Starting Threshold 6

Damping Ratio 6

Field Tests 6

Future Refinements 8

Conclusions 8

Acknowledgments 9

References 9 


\section{List of Figures}

Figure 1. Fiber optic vane with light source/electronics housing and cabling 2

Figure 2. Schematic of the fiber optic wind vane 3

Figure 3. The inside of the fiber-optic wind vane. The gray code wheel and termination/alignment block are barely visible. 4

Figure 4. View inside of the light source/electronics housing showing the light source (white box on the right), single fibers mounted into the termination block with wires extending from beneath the photodetectors (middle), and signal processing circuitry (foreground) 4

Figure 5. The Building 735-7A Meteorological Engineering Facility including the wind tunnel 5

Figure 6. Output voltage per degree of azimuth for the fiber optic wind vane 5

Figure 7. Fifteen-minute averages of wind direction of the Model $020 \mathrm{C}$ versus the fiber optic wind vanes

Figure 8. Fifteen-minute averages of the standard deviation of wind direction as measured by the fiber-optic wind vane versus that measured by the Model $020 \mathrm{C} 7$

Figure 9. The difference in wind direction measurements of the fiber-optic wind vane and the Model $020 \mathrm{C}$ versus wind speed during the experiment 9

Figure 10. Same as Figure 7 except for the difference in the standard deviation of wind direction is shown 10

Figure 11. Time series plot of fifteen-minute averages of the standard deviation of wind direction measurements by the fiber optic and the Model $020 \mathrm{C}$ wind vanes and the wind speed over the entire experiment 10

Figure 12. Same as for Figure 9 except the values are plotted versus the time of day 11

\section{List of Tables}

Table 1. Specifications of the Fiber Optic Wind Vane 8 


\section{Executive Summary}

A Cooperative Research and Development Agreement (CRADA) between Met One Instruments, Incorporated (Met One) and Westinghouse Savannah River Company (WSRC) was made to develop and test a fiber optic measurement-based wind vane. Some advantages of using fiber optic technology for a wind vane include protection against lightning-induced electrical surges and radio-frequency interference, suitability for use in explosive environments, and a longer field life. A prototype fiber optic wind vane was built by Met One and tested by WSRC. Wind tunnel test results indicated that the vane is very sensitive to low wind speeds ( $<0.15$ meter per second) although the resolution of the sensor ( 1.4 degrees) is higher than typical wind vanes. A side-by-side field test with a conventional commercial wind vane indicated that the fiber optic wind vane performed well and even cutperformed the conventional sensor during low wind speed conditions. The field test also indicated that the fiber optic sensor is a viable instrument although some modifications are required before the sensor can be readily commercialized.

\section{Introduction}

The Atmospheric Technologies Group (ATG) of WSRC currently maintains a network of ten meteorological observation towers to provide timely, accurate data for emergency response to unplanned atmospheric releases of hazardous materials or chemicals and to provide databases for dosimetric, engineering, and environmental studies (Parker and Addis 1993). This network of towers is part of the Savannah River Technology Center's (SRTC) Weather INformation and Display (WIND) System. Since 1987, nine of the ten towers have been equipped with Met One equipment. Through extensive testing and calibrations, Met One's equipment has been proven to be dependable, accurate, and durable.

In 1993, Met One Instruments purchased the meteorological instruments division of Teledyne Geotech. Met One maintained most of Teledyne Geotech's technical personnel and the Model 1585 Bivane as one of their products. In 1994, a CRADA (CR-94-010) between WSRC and Met One Instruments was created to develop an aerodynamically enhanced bi-directional wind vane to provide better measurements of atmospheric turbulence (Parker 1996). During the course of interaction betwreen ATG and Met One, discussions concerning the development of fiber optic meteorological sensors were made. Met One proposed to develop a fiber optic measurement-based wind vane and requested that ATG assist in wind tunnel and field testing. The potential advantages of using fiber optic technology in a meteorological instrument include:
- Fiber optics are impervious to lightning-induced electrical surges.

- Fiber optics are impervious to radio frequency interference (RFI) commonly created by radio/television/ microwave transmission on tall towers.

- This technology employs non-electrical components, which could be used in explosive environments.

- This technology has a lower starting threshold.

- Fewer physical contact points are used, meaning less wear and a longer field life.

- Fiber optics have a high signal to noise ratio.

- This technology provides increased measurement precision, resolution, linearity, and accuracy.

For WSRC, a fiber optic measurement-based meteorological sensor could be used to greatly reduce problems from RFI and lightning surges as well as improve precision, resolution, linearity, accuracy, and longevity. As a result of these discussions, a CRADA (CR-94-015) between Met One and WSRC was created to develop a fiber-optic-based wind direction sensor.

\section{Sensor Design}

The design of the fiber-optic wind vane (Figure 1) is simple in concept and markedly different from a typical fiber optic application. The vane uses a mechanical device to operate, which contrasts with fiber-optic communication applications that optimize the high speed and capacity capabilities of fiber. For this meteorological application, the fiber-optic wind vane capitalizes on a unique set of characteristics offered by fiber optics that meet the criteria discussed in the previous section. Thus, meteorology is borrowing from communication technology. 


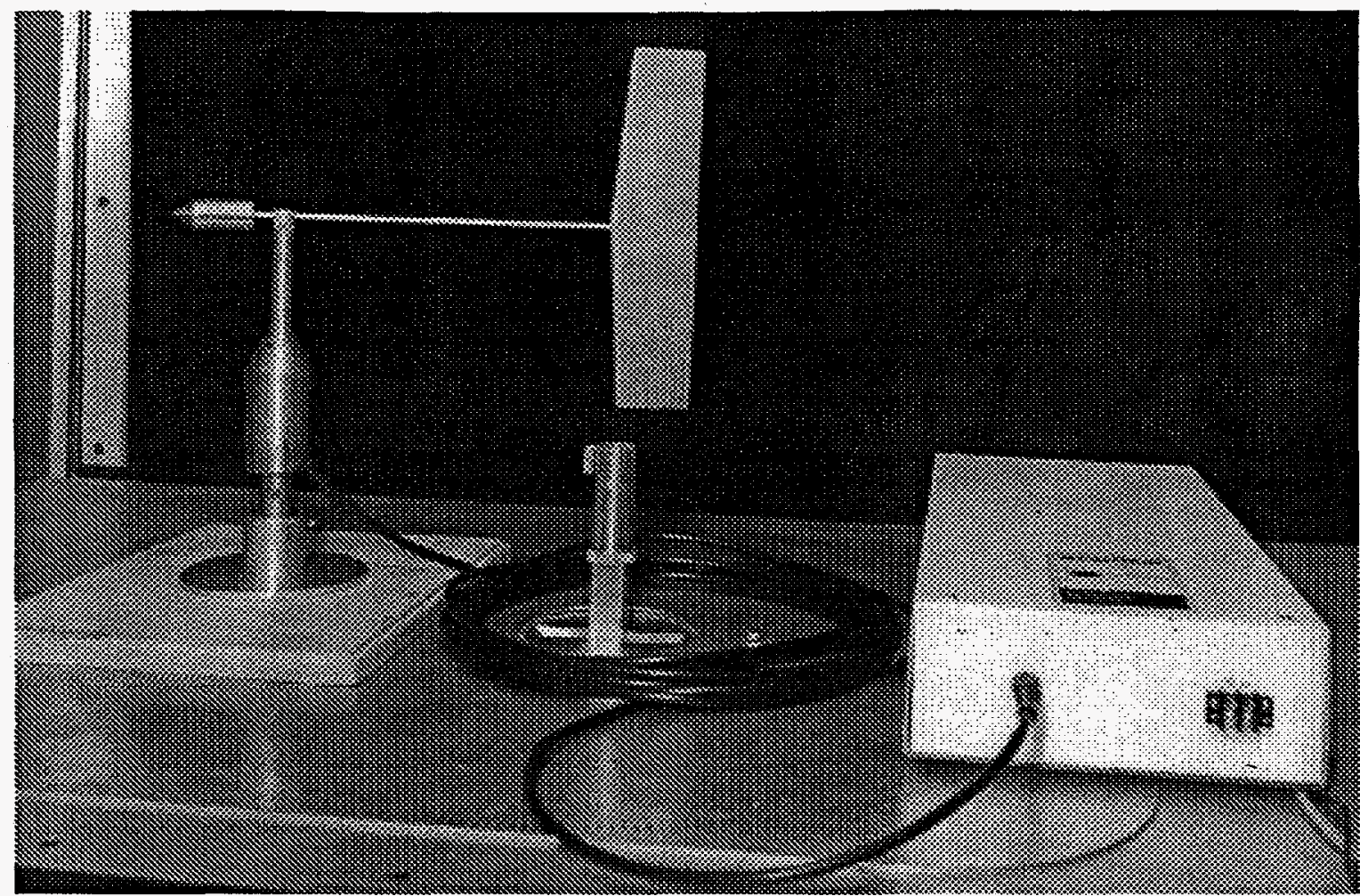

Figure 1. Fiber optic vane with light source/electronics housing and cabling

Figure 2 shows a schematic of the fiber-optic wind vane. Light travels from the source through plastic fiber cabling to the base of the wind vane. At this point, the fiber terminates into a lens fitted with a coupling that contains eight thin strands of plastic fiber. These strands extend into a termination block inside the sensor. The block acts as an alignment holder. An identical set of thin fiber strands are mounted on the opposite side of the block directly beneath the upper part of the block. In between the thin strands is an eight-channel binary code wheel that is attached to the shaft of the sensor and is perpendicular to the block (Figure 3). The shaft and wheel rotate as the vane at the top of the instrument rotates. The binary code wheel, by its design, can either allow light to pass between the fibers or block the light. Pulses of light enter the strands at the bottom of the block and travel back to the light source inside the same wiring jacket.

The light source, fiber cabling origination and termination points, and signal processing hardware are located in one housing (Figure 4) that must be placed inside a weatherproof shelter. The light source must provide enough light to be able overcome the considerable attenuation that occurs at all key junctures along the light pathway. The two junctures that cause the most attenuation of light are at the coupling and the alignment block.
Each of the eight return fiber strands terminates into a block where a set of photodetectors are mounted. Each photodetector converts the detection of light from an individual strand into an analog output voltage. All eight photodetectors transmit individual signals to a circuit board, which is programmed to convert the digital logic of the binary code into a linear voltage output that is directly related to the angle of the wind direction. In this case, the voltage output is 0 to 5.000 volts DC for the 0 to 360 degrees range of wind direction. The output voltage is sent to a terminal strip for external sampling. The length of the available cabling for the prototype was limited to $\mathbf{1 0}$ meters, which is a typical monitoring height for wind vanes.

The resolution of the sensor is limited by the configuration of the binary code wheel. The calculation of the resolution is made by taking the number of degrees (360) and dividing by the number of possible combinations of the binary code wheel $\left(2^{8}=256\right)$. Therefore, the resolution is 1.4 degrees. Typical wind direction sensors have resolutions of less than 0.1 degree, which is considerably less than the fiber-optic prototype vane. Figure 5 shows the output voltage per degree for the prototype vane. 


\section{Design Schematic of the Fiber Optic Wind Vane}

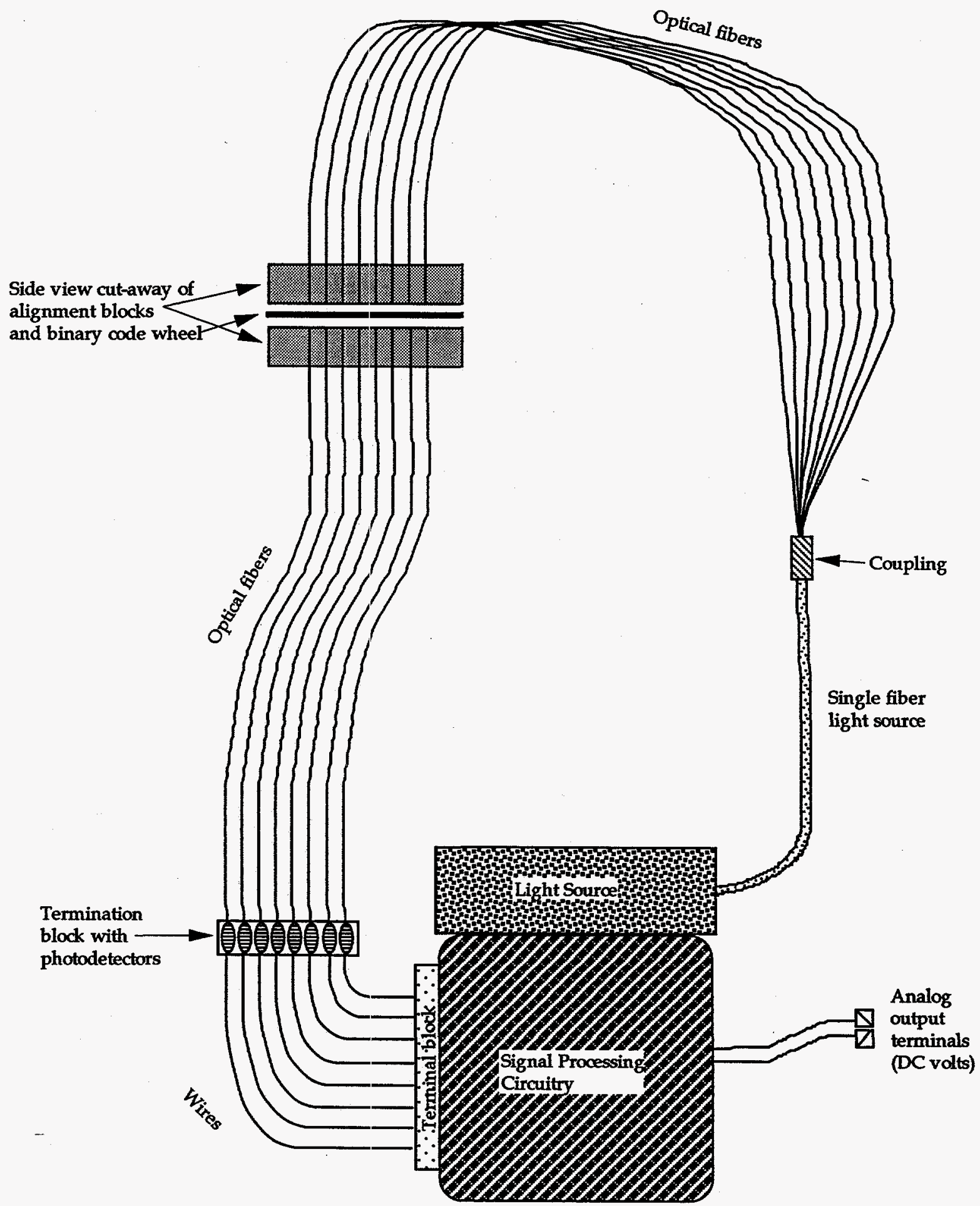

Figure 2. Schematic of the fiber optic wind vane 


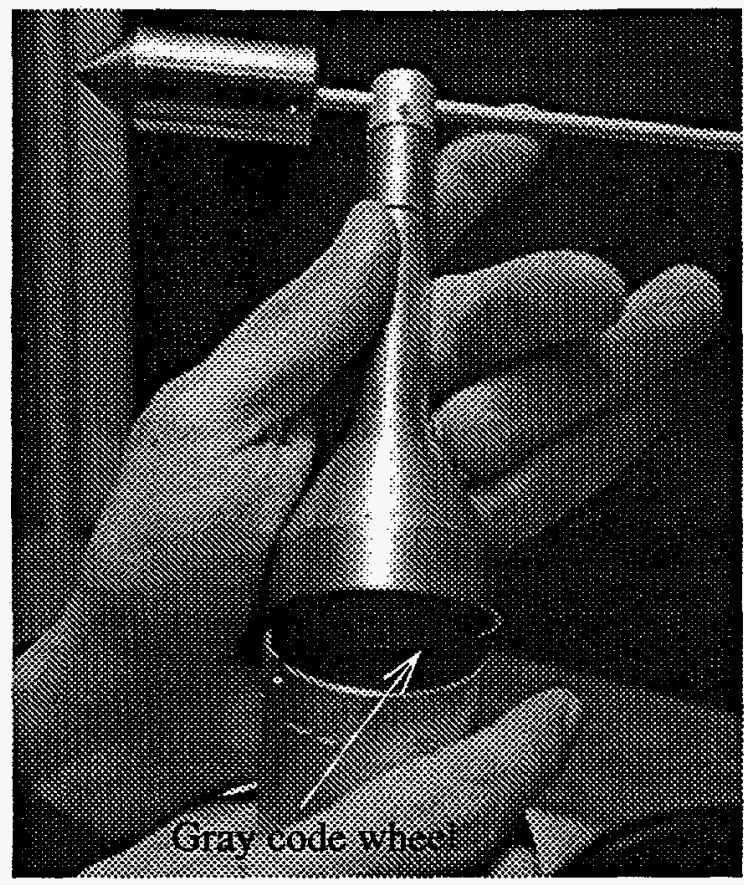

Figure 3. The inside of the fiber-optic wind vane. The gray code wheel and termination/alignment block are barely visible.
The outer casing of the sensor is made of machined aluminum, and the top diameter of the sensor is identical to the Met One $020 \mathrm{C}$ wind direction sensor to allow the use of an $020 \mathrm{C}$ vane assembly. A strain relief fitting has been attached to support the fiber optic wiring jacket near the bottom of the outer case on an offset face. The base of the sensor is a $2.54-\mathrm{cm}$ shaft that is $7.9 \mathrm{~cm}$ long.

\section{Wind Tunnel Tests}

Westinghouse Savannah River Company operates an Aerolab subsonic wind tunnel in the Building 735-7A Meteorological Engineering Facility (Figure 6). The tunnel functions by drawing air through the tunnel structure with a motorized fan. The air enters the wind tunnel through a honeycomb filter that limits the size of turbulent eddies entering the tunnel. After passing through the filter, air continues through a section of areal reduction to the test section of the wind tunnel. The air flow rate through the test section is readily controlled by regulating the rate of rotation of the fan blades. Turbulent eddies are virtually non-existent in the test section, which creates an ideal testing platform inside the wind tunnel. Air flow can be regulated from approximately 0.15 to 23 meters per second. Calibrations are made with standards traceable to the National Institute for Standards and Testing (NIST).

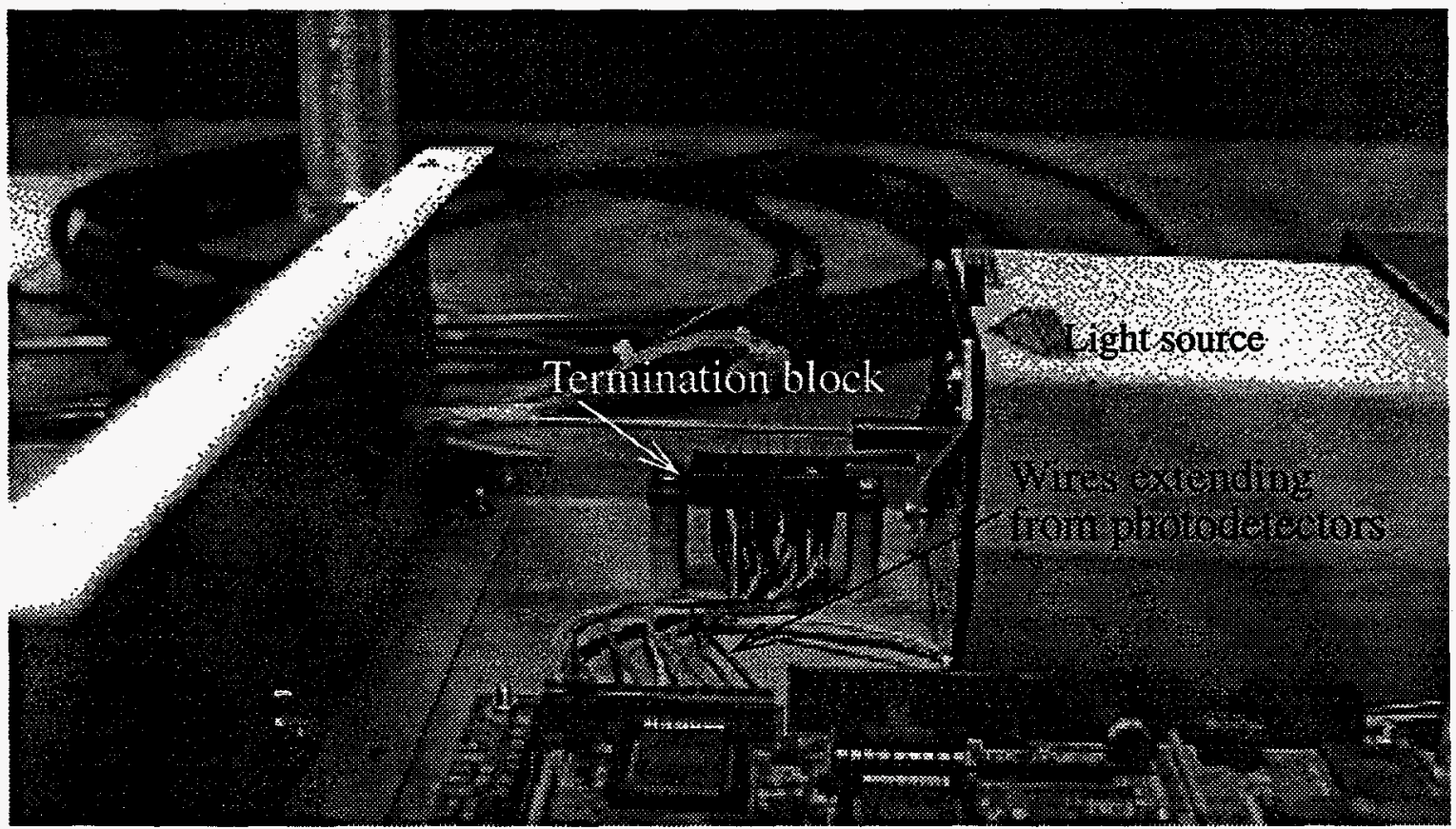

Figure 4. View inside of the light source/electronics housing showing the light source (white box on the right), single fibers mounted into the termination block with wires extending from beneath the photodetectors (middle), and signal processing circuitry (foreground) 


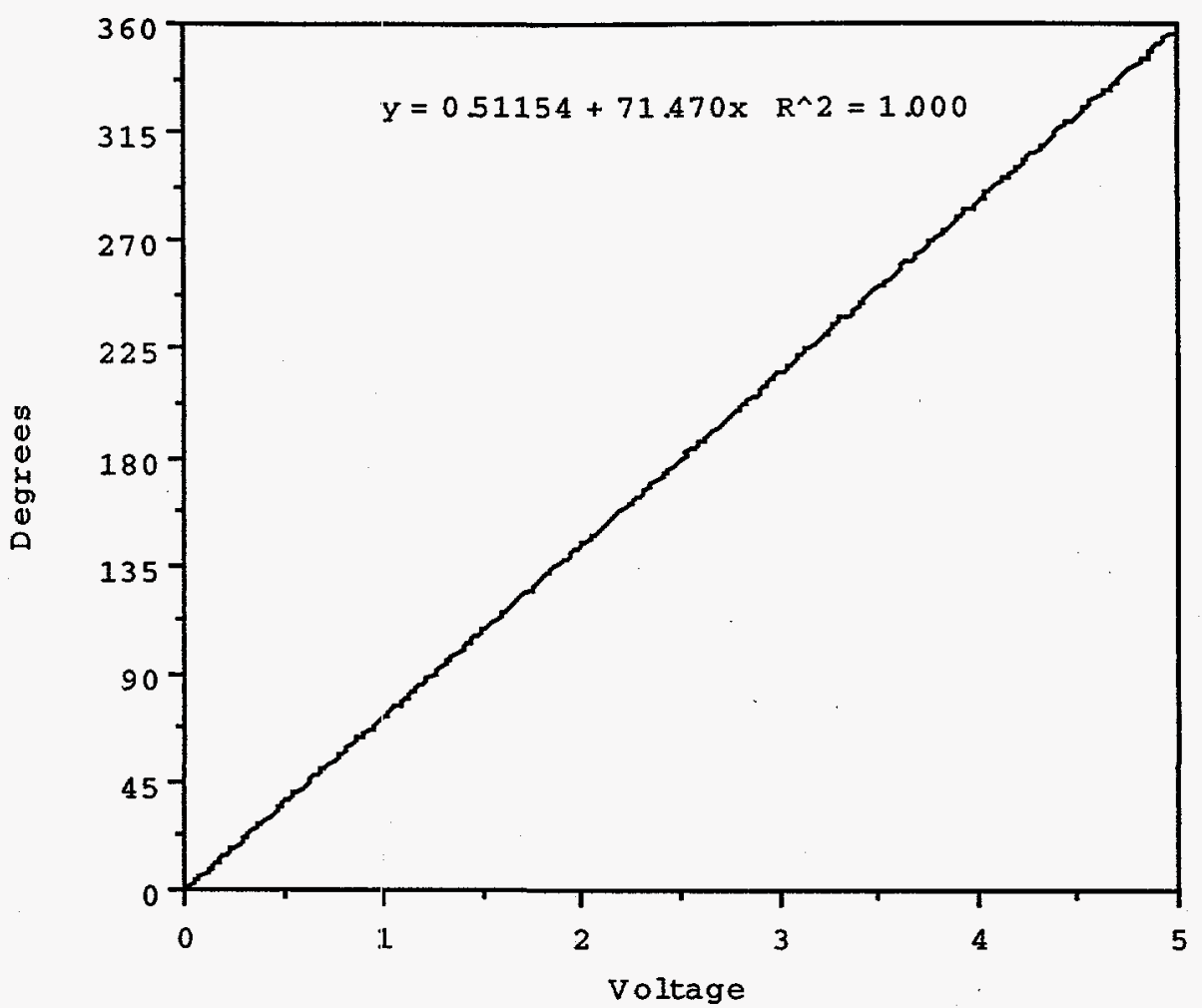

Figure 5. Output voltage per degree of: azimuth for the fiber optic wind vane

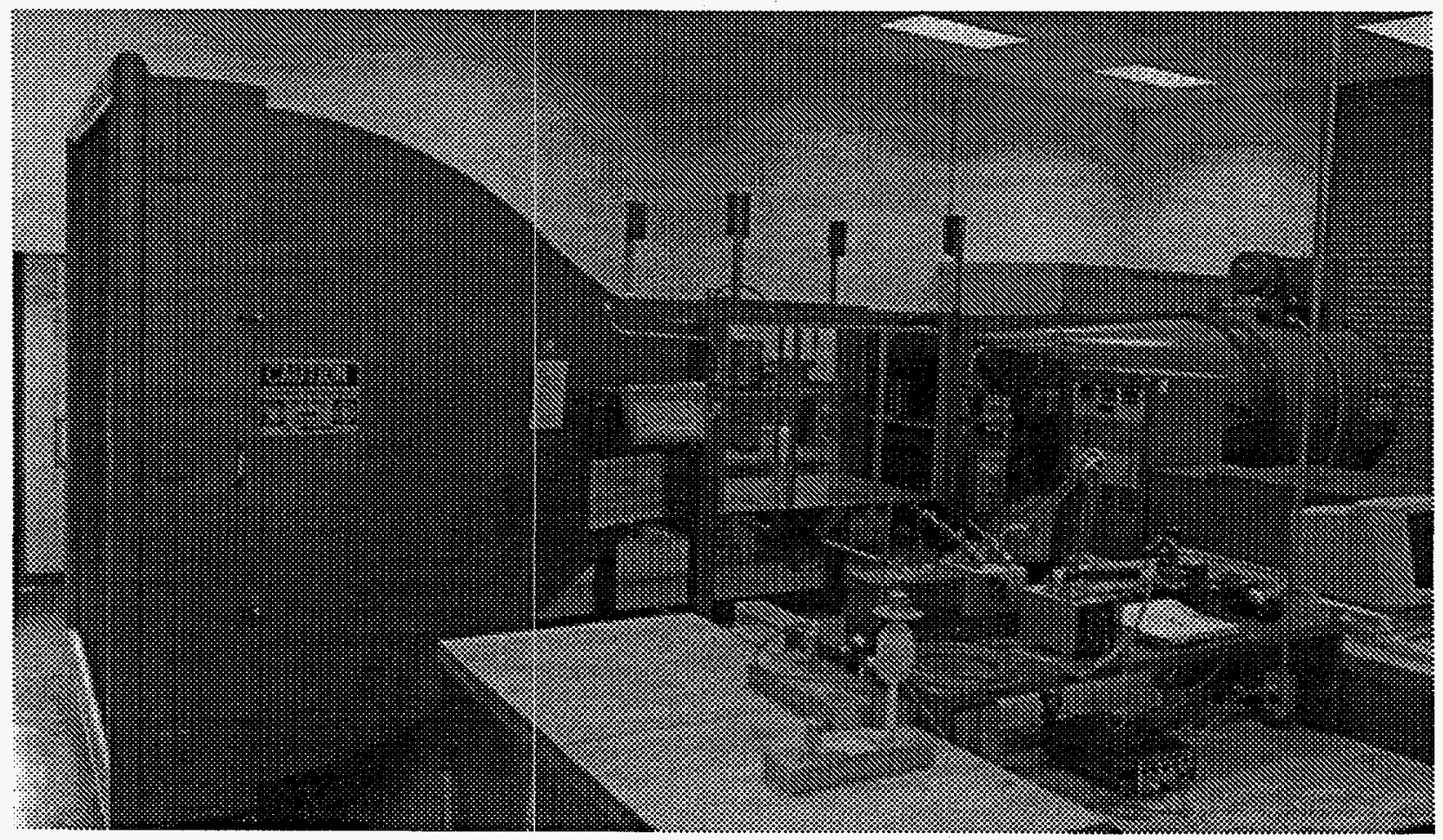

Figure 6. The Building 735-7A Meteorological Engineering Facility including the wind tunnel. 
A three-dimensional positioning arm is used as a release mechanism in the rear of the tunnel test section. Repeatability of the positioner can be easily accomplished to onetenth of one horizontal degree. The release mechanism does not impart any additional force to the vane upon release.

Data acquisition is performed with Labtech Notebook on a personal computer. Data sampling rates can be varied, but 200 hertz was commonly used for all wind tunnel tests. Data storage files were made in the random-access memory to enhance data sampling rates, and permanent files were stored onto the hard drive of the personal computer. Data analyses were conducted after the data were stored.

Wind tunnel tests of the dynamic vane bias, starting threshold, and damping ratio were made in the Building 735-7A Meteorological Engineering Facility. The results of these tests are discussed in the following sections.

\section{Dynamic Vane Bias}

The dynamic vane bias is a measured by aligning the vane of the prototype to the wind tunnel centerline with no air flow and comparing this value to a measurement at 5 meters per second (ASTM 1995). Normally, the vane bias is expected to be less than one degree. The vane bias for the fiber optic vane was acceptable since the same degree measure was made at 5 meters per second as at a zero air flow. The true vane bias was likely between 0 and 1.4 degrees or the resolution of the sensor.

\section{Starting Threshold}

The starting threshold of a wind vane is determined by placing the vane at a ten degree offset to the tunnel flow and determining the lowest flow at which the vane is displaced at least one degree (ASTM 1995). The vane was found to be responsive at 0.15 meter per second in the wind tunnel. It is likely that the true starting threshold is less than 0.15 meter per second since the total vane displacement was well over 10 degrees as the vane aligned itself with the tunnel centerline. A flow rate of 0.15 meter per second is the extreme lower limit of the wind tunnel.

\section{Damping Ratio}

The damping ratio is a measure of a vane's ability to respond to a step function change in wind direction (ASTM 1995). Calculations of the "unitless" damping ratio allow intercomparison of vane types and styles. In general, the damping ratio should be 0.4 or greater for wind direction sensors used to provided data for calculations of atmospheric dispersion. To measure the damping ratio, the vane is held at a ten degree offset angle and released. Three key measurements are made during the testing process: release point, maximum displacement, and final vane location resulting from the tunnel air flow alone.

Tests of the damping ratio were found to be incompatible with the fiber-optic wind vane prototype due to the relatively large degree angle resolution. Since the resolution of the vane is 1.4 degrees, the uncertainty in the measurements of the release point and overshoot angle could be as much as 2.8 degrees combined. This equates to a possible range in the damping ratio of about 0.2 (very poor) to 0.7 (excellent). Therefore, tests of the damping ratio were unsuccessful.

\section{Field Tests}

A short-term field test of the fiber optic wind vane prototype was made to challenge the viability of the sensor under real environmental conditions. A side-by-side test with a Met One $020 \mathrm{C}$ wind vane was made on a portable tower which was situated at the Central Climatology facility (Kurzeja 1993; Parker and Addis 1993) at the SRS. The sensors were mounted at 6.7 meters on a 1-meter crossarm. The tower was located adjacent to a 3.7 meter high building to facilitate the limited fiber-optic cabling available with the sensor. Data were collected at a frequency of 1 hertz, and 15-minute averages were stored. Data were also sampled from a Met One Model 1564B anemometer with a sensitive 6-cup assembly permanently installed at the 4 meter level of the Central Climatology tower located about 22 meters from the portable tower. Wind speed data were handled in an identical manner on the same data logger.

Figure 7 shows a plot of the wind direction as measured by the Model $020 \mathrm{C}$ versus the fiber sensor. As can be seen, most points fell along the " $y=x$ " line, but the actual ideal fit line deviates from the one-to-one line. Several points fall well beyond either line and this will be discussed in the following sections. Figure 8 shows the standard deviation of wind direction of the fiber sensor plotted against the standard deviation of the wind direction of the Model $020 \mathrm{C}$. Again, most points lie along the " $y=x "$ line, but the actual best fit line has been adjusted to compensate for the large number of large "Sig Fiber" values that occurred when the value of "Sig 020C" was near 0 degrees.

The performance of each sensor can be assessed further with an additional analysis of the wind speed. Figure 9 shows the difference in wind direction measurements of the fiber and the Model $020 \mathrm{C}$ sensors along with the wind speed during the field test. The largest magnitude of the differences were observed during low wind speed conditions. (There is also a bias of 2.1 degrees between the sen- 


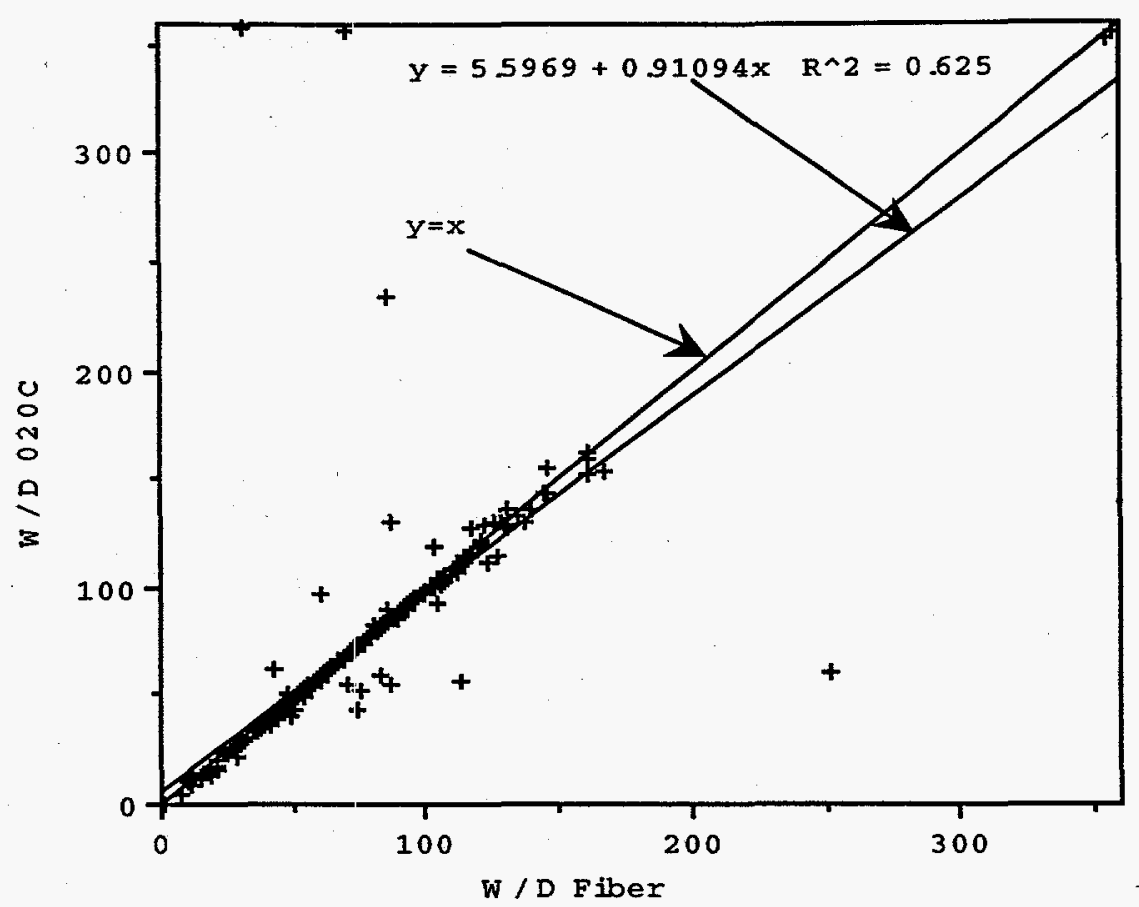

Figure 7. Fifteen-minute averages of wind direction of the Model $020 \mathrm{C}$ versus the fiber optic wind vane.

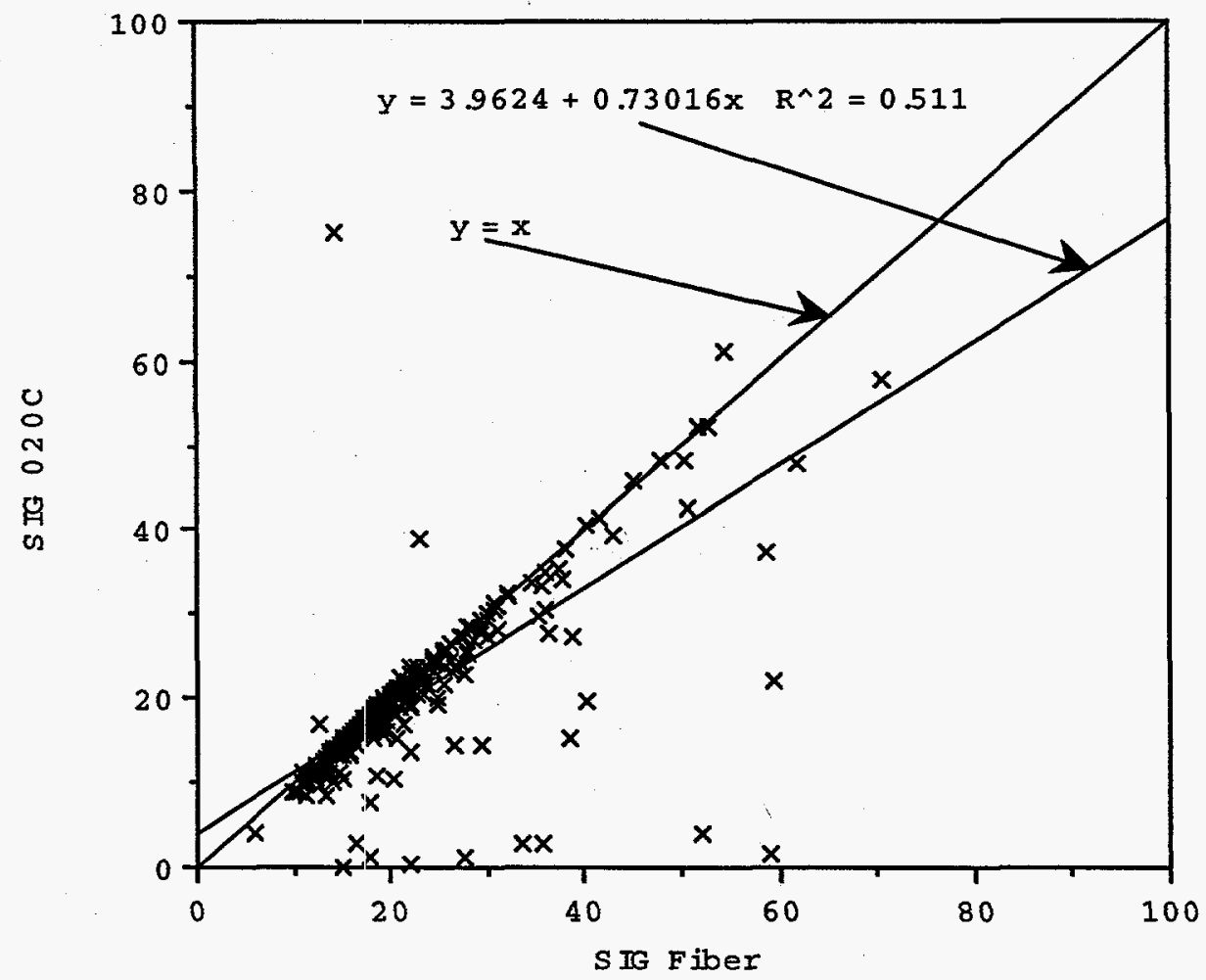

Figure 8. Fifteen-minute averages of: the standard deviation of wind direction as measured by the fiber-optic wind vane versus that measured by the Model $020 \mathrm{C}$. 
sors, which was likely the result of sighting errors.) Figure 10 shows the difference in the values of the standard deviation of the wind direction between the two sensors and the wind speed. Again, the largest magnitude of the differences occurred during the times of low wind speeds. Figure 11 shows the actual values of the standard deviations of wind direction for both sensors along with the wind speed. At speeds above 0.5 meter per second, the standard deviations were nearly identical; however, at speeds below 0.5 meter per second, the values for each sensor differed greatly. In fact, the Model $020 \mathrm{C}$ measured values of near 0 degrees during the periods of wind speeds less than 0.5 meter per second whereas the fiber sensor provided larger standard deviations. The Model $020 \mathrm{C}$ was likely not moving since the wind speed was below the vane's starting threshold. On the other hand, the fiber sensor was still operating since its starting threshold, as measured in the wind tunnel, is much lower than the starting threshold of the Model $020 \mathrm{C}$. There was some exaggeration of the standard deviations of the fiber vane due to the likely temporary "sticking" during essentially calm conditions (Parker 1996).

Figure 12 shows that the most likely time of day for the Model $020 \mathrm{C}$ to record a low value of the standard deviation was during the evenings and the periods just after midnight. It is interesting to note that the presence of dew accumulations near the sunrise hours (0500-0700 local time) did not appreciably affect either sensor. Again, the occurrence of high values of the standard deviations occurred at very low wind speeds.

This field test did not effectively challenge the ability of the fiber-optic wind vane to remain impervious to lightning-induced electrical surges or RFI. The test was conducted under warm, humid summertime conditions, but no thunderstorms occurred. One period of light rain was recorded just before daybreak of the fourth day, but this rain had no noticeable effect on the data. Each sensor in the field test was tied into the grounding grid for the nearby observation tower. There are no known sources of RFI at the field test site.

\section{Future Refinements}

There are several aspects of the fiber-optic wind vane prototype that must be improved before the sensor can become a commercially viable product. The primary areas of concern are the resolution of the sensor, light attenuation in the fiber optic cabling, and the utilization of connectors to allow interchangeability of sensors.

The resolution of the sensor must be increased to attain a level consistent with common commercial wind vanes.
This can be accomplished by utilizing a nine-digit binary code wheel. This would give a resolution of 0.7 degree compared to 1.4 degrees for the prototype. If possible, a ten-digit wheel could be used to increase the resolution to 0.35 degree, but this may be difficult due to cross-contamination of light near each opening of the binary code wheel.

Light attenuation in the fiber-optic cabling must be minimized at each connection point. The loss of light at connections is symptomatic of all fiber-optic applications but can be minimized through the use of lenses, such as a collimator, which refocus light through each side of a connector.

The fiber-optic wind vane prototype was "hard-wired" through the sensor without a means of changing sensors. This was an acceptable practice for a prototype but is not acceptable for a commercial product. A suitable fiberoptic connector at the sensor will be required to allow interchangeability between sensors. Otherwise, with a hard-wired sensor, the entire sensor and cabling system would be replaced in the event of a non-field calibration or failure.

\section{Conclusions}

A fiber optic measurement based wind vane was developed during the course of this CRADA. Wind tunnel tests indicated that the sensor is responsive to wind speeds as low as $\mathbf{0 . 1 5}$ meter per second. This compares favorably to typical commercial wind vanes which are responsive to speeds of 0.5 meter per second or greater. However, the relatively poor resolution (1.4 degrees) of the fiber optic wind vane hampered further wind tunnel tests of the damping ratio and distance constant since the error involved in making measurements approached $30 \%$, and hence, a factor of three error in the damping ratio. A suggested refinement to the increase the resolution of the sensor by a factor of two could be made rather simply in future prototypes.

A short-duration field experiment was used to test the viability of the fiber optic sensor and to compare its performance to a commercially available wind vane. The standard deviations of the horizontal wind direction measured by each sensor were nearly identical except under low wind speed conditions. The superior responsiveness of the fiber sensor to low wind speeds resulted in more accurate measurements than the commercial sensor. When the wind speed dropped below 0.5 meter per second, the commercial sensor became unresponsive but the fiber sensor was able to continue to make accurate measurements of the wind direction unless the wind speed dropped below 0.15 meter per second. 
Tests of the fiber optic wind vane against lightning induced electrical surges and radio-frequency interference were not made. Table 1 identifies the specifications of the fiber optic wind vane.

Table 1. Specifications of the Fiber Optic Wind Vane

\begin{tabular}{|l|l|}
\hline Resolution & 1.4 degrees \\
\hline Starting threshold & $<0.15$ meter per second \\
\hline Vane bias & 1.4 degrees \\
\hline Damping ratio & indeterminate \\
\hline Distance constant & indeterminate \\
\hline
\end{tabular}

\section{Acknowledgments}

This work was partially funded under contract DE-AC0989SR18035 with the United States Department of Energy and by Met One Instruments, Incorporated, Grants Pass, Oregon. Special thanks for diligent assistance to Randy Holland and John T. Hamilton, Jr. of WSRC and Dennis Recla of Met One.

\section{References}

ASTM, 1995, "Standard Test Method for Determining the Dynamic Performance of a Wind Vane", D5366-95 in volume 11.03, Atmospheric Analysis; Occupational Health and Safety; Protective Clothing, American Society for Testing and Materials, Philadelphia, PA.

Kurzeja, R. J., 1993, The Savannah River Technology Center Research and Development Climatology Center, WSRC-TR-93-596, Savannah River Technology Center, Westinghouse Savannah River Company, Aiken, SC 29808.

Parker, M. J. and R. P. Addis, 1993, The Meteorological Monitoring Program at the Savannah River Site, WSRC-TR-93-0106, Savannah River Technology Center, Westinghouse Savannah River Company, Aiken, SC 29808.

Parker, M. J., 1996, “A New Low Threshold Bi-Directional Wind Vane and Its Potential Impact on Unplanned Atmospheric Release Prediction", Preprint of the Ninth Joint Conference on the Applications of Air Pollution Meteorology with the A\&WMA, 28 Jan-2 Feb, 1996 in Atlanta, Georgia, American Meteorological Society, Boston, MA.

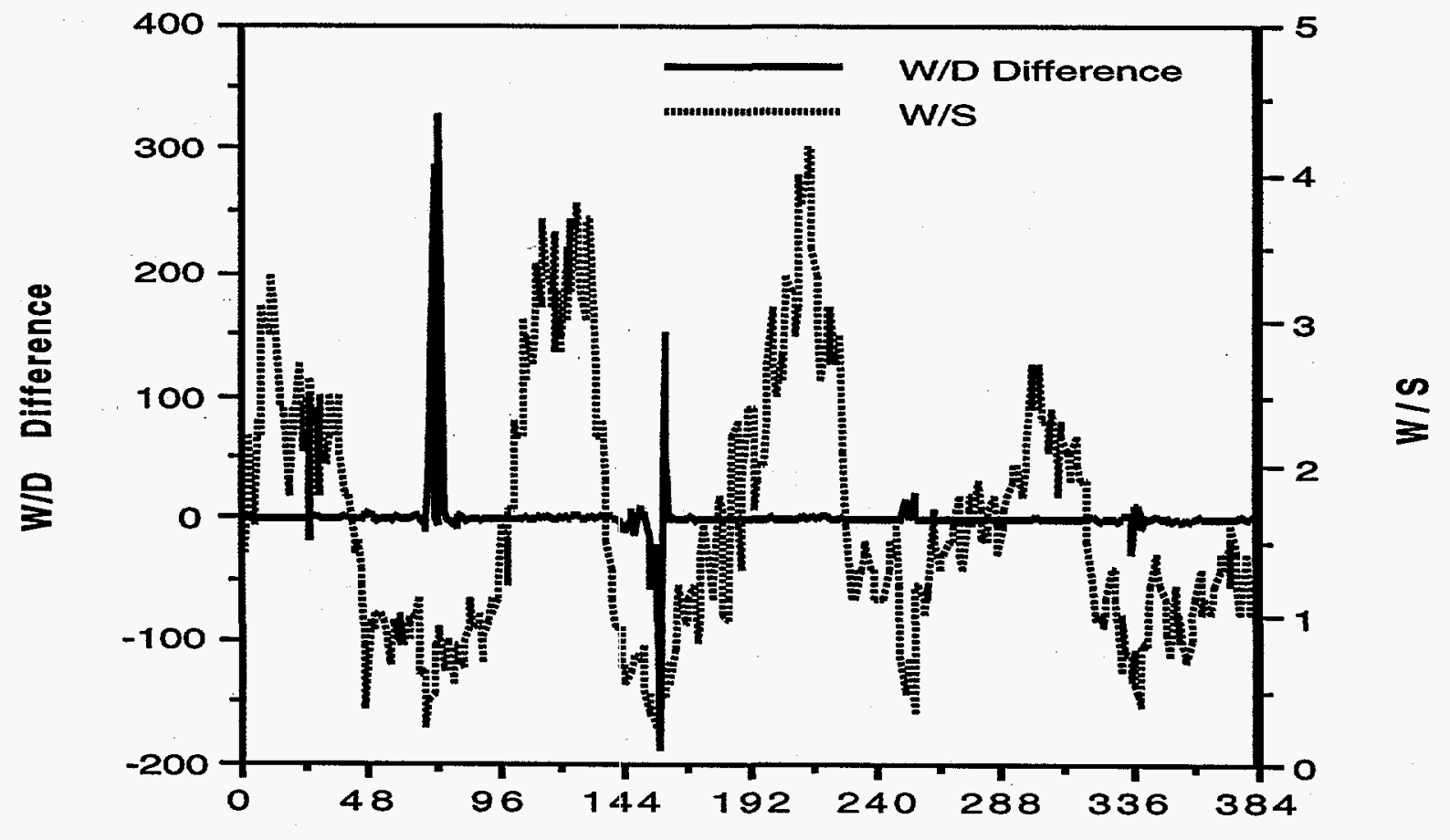

Hour of experiment

Figure 9. The difference in wind direction measurements of the fiber optic wind vane and the Model $02 \mathrm{C}$ versus wind speed during the experiment. The greatest difference occurred under low wind speed conditions when the fiber sensor proved to be more responsive (see the section on Field Tests). 


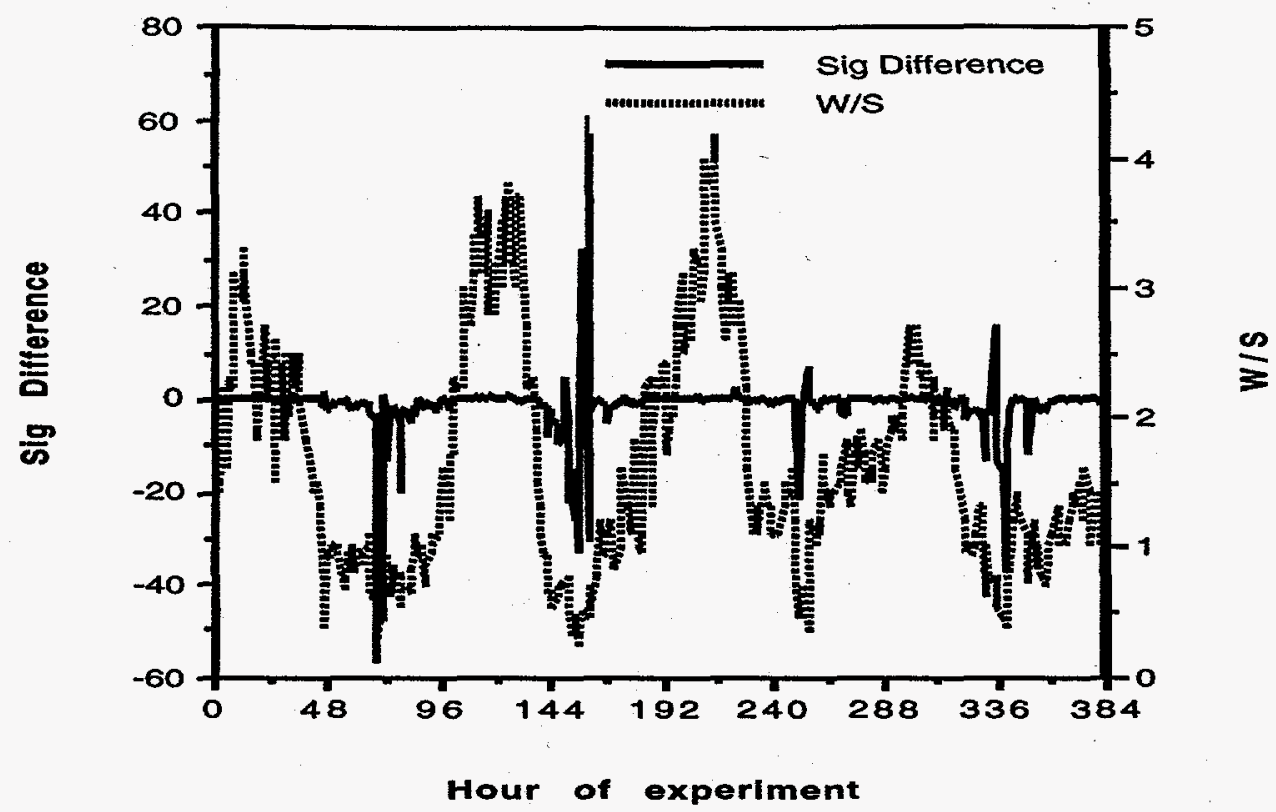

Figure 10. Same as Figure 9 except for the difference in the standard deviation of wind direction is shown. As in Figure 9 , the greatest difference occurred under low wind speed conditions when the fiber sensor proved to be more responsive (see the section on Field Tests).

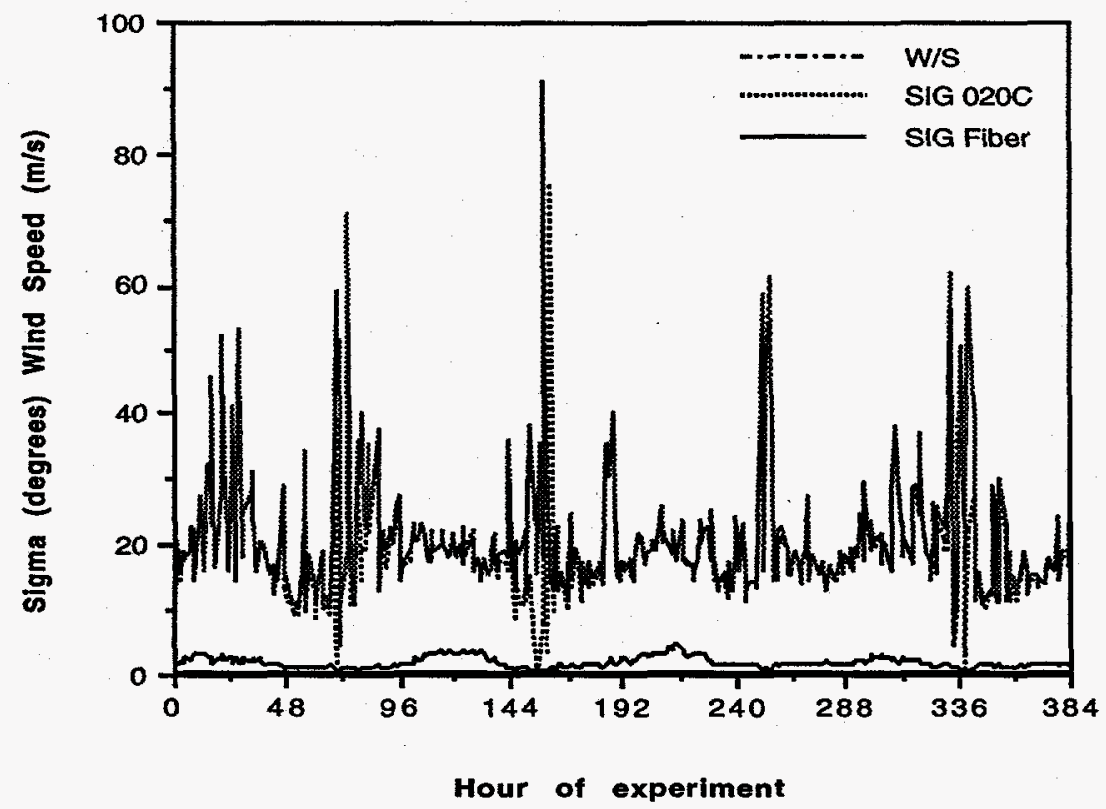

Figure 11. Time series plot of fifteen-minute averages of the standard deviation of wind direction measurements by the fiber optic and Model $020 \mathrm{C}$ wind vanes and the wind speed over the entire experiment. Values of the standard deviation were nearly identical except under low wind speed conditions when the fiber sensor proved to be more responsive (see the section on Field Tests). 


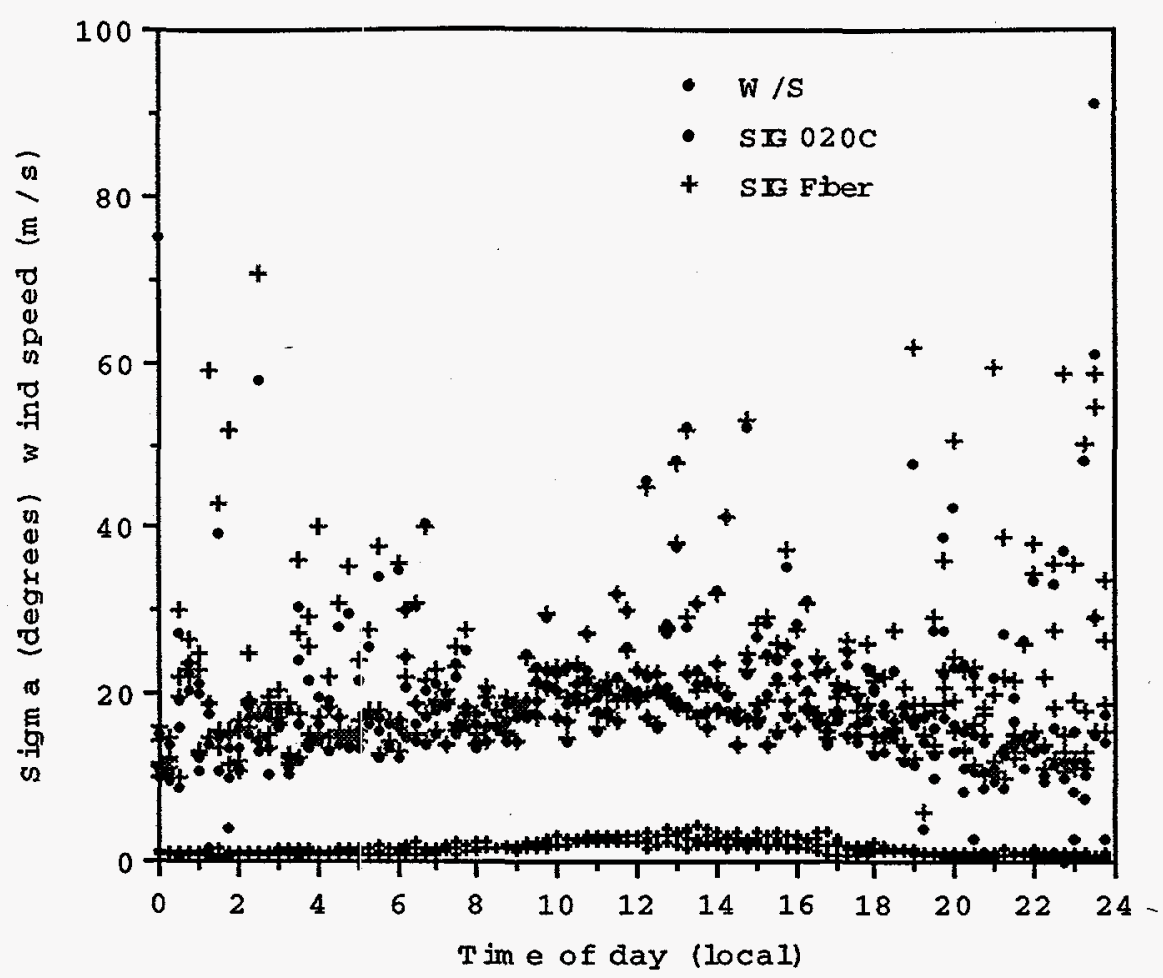

Figure 12. Same as for Figure 9 except the values are plotted versus the time of day. 


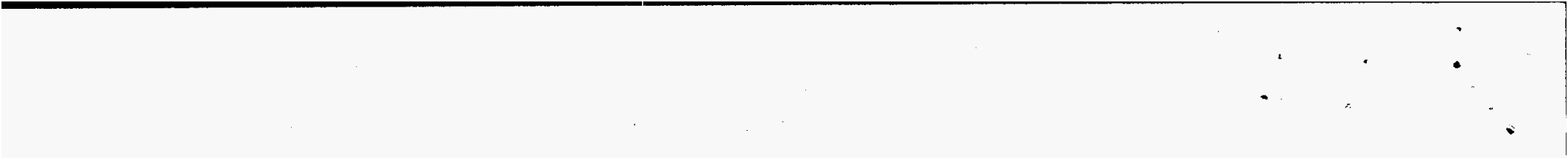

